\title{
Synthesis, Characterization and DFT Analysis of Benzimidazolylpyrazolylacrylonitrile
}

\author{
Ramar Sivaramakarthikeyan, Krishnaraj Padmavathy, Shunmugam Iniyaval, \\ Chennan Ramalingan
}

\begin{abstract}
A novel heterocyclic molecule possessing two important scaffolds such as pyrazole and benzimidazole was synthesized and the structure of the same was corroborated based on analytical and spectroscopic techniques. The molecular structure of 6 was optimized; FMO energies associated properties were calculated. The hyperpolarizability $\left(\beta_{\text {tot }}\right)$ and electric dipole moment $\left(\mu_{\text {tot }}\right)$ of 6 were computed. When compared to urea, the $\beta$ was 7.6 times superior, which validate the target 6 may serve as a candidate for NLO applications.
\end{abstract}

\section{Keywords: HOMO-LUMO, Electrophilicity index, NLO.}

\section{INTRODUCTION}

In current decade, the organic materials have attained the interest of material chemists/scientists around the globe due to their outstanding approaches for the utilization of donor-acceptor (D-A) combinations in achieving specific targets. These materials display a wide spectrum of applications in the field of organic light emitting diodes (OLEDs) [1-3], lasers [4], various types of solar cells in particular organic / dye-sensitized solar cells (DSSCs) [5], field-effect transistors (FETs) [6,7] and sensors [8]. Particularly, organic materials display efficient nonlinear optical properties (NLO) and rapid responsiveness due to the presence of highly movable electrons. Pyrazole is one of the important five membered heterocyclic compounds with a couple of nitrogen's at adjacent positions (i.e., 1, 2 positions) in its aromatic structural motif. Pyrazole analogous exert a wide variety of not only biological properties [9-15], but also exert a diverse range of electronic properties. Some of the other specific applications of pyrazole includes electroluminescence (EL) properties [16], semiconductors [17], liquid crystals [18], organic light emitting diodes (OLEDs) [19] and solar cells [20]. It has also been reported

Revised Manuscript Received on December 15, 2019.

* Correspondence Author

Ramar Sivaramakarthikeyan, Department of Chemistry, School of Advanced Sciences, Kalasalingam Academy of Research and Education (Deemed to be University), Krishnankoil, 626 126, Tamilnadu, India. Email: sivaram.ramar@gmail.com

Krishnaraj Padmavathy, Department of Chemistry, School of Advanced Sciences, Kalasalingam Academy of Research and Education (Deemed to be University), Krishnankoil, 626 126, Tamilnadu, India. Email: ovshada@gmail.com

Shunmugam Iniyaval, Department of Chemistry, School of Advanced Sciences, Kalasalingam Academy of Research and Education (Deemed to be University), Krishnankoil, $626 \quad 126$, Tamilnadu, India. Email: iniyaval.s@klu.ac.in

* Chennan Ramalingan, Department of Chemistry, School of Advanced Sciences, Kalasalingam Academy of Research and Education (Deemed to be University), Krishnankoil, $626 \quad 126$, Tamilnadu, India. Email: ramalinganc@gmail.com that ethoxy carbonyl substituted pyrazolyl benzoic acid as potential NLO materials [21].

On the other hand, benzimidazole is another nitrogen heterocyclic compound with two nitrogen atoms at alternate positions. Similar to that of pyrazole, benzimidazoles also possess an extensive range of bioactivities [22-27]. Also, from literature, benzimidazolium phthalate was found to show non-linear optical properties with second harmonic generation efficiency, 0.3 times greater than that of standard urea [28]. Thus, we propose to synthesize a scaffold with both pyrazole and benzimidazole moieties with extended conjugation with an idea of enhancing the NLO properties. The structure of the molecule was established using spectroscopic techniques. Further, the structural optimization, HOMO-LUMO analysis, NLO studies and associated quantum parameters were determined by subjecting into computational calculations.

\section{EXPERIMENTAL SECTION}

\section{A. General}

The reagent / solvents utilized in this piece of work were obtained through commercial sources and used as such / purified through standard procedure before their use. Progress and completion of the reactions were checked TLC (Merck). All melting points reported were measured in Sigma MP apparatus (open capillaries). IR spectra were recorded as KBr pellet using Shimadzu-IR Tracer 100 spectrophotometer. ${ }^{1} \mathrm{H}$ and ${ }^{13} \mathrm{C}$ NMR spectra were recorded on Bruker AVANCE III (400 and $100 \mathrm{MHz}$ ) NMR spectrometer at $25^{\circ} \mathrm{C}$. Chemical shift values are expressed in terms of ppm.

\section{B. Synthesis of carbaldehyde 4}

Stirred a mixture of 4-methylacetophenone $(0.01 \mathrm{~mol})$ and phenyl hydrazine $(0.01 \mathrm{~mol})$ in glacial acetic acid $(10 \mathrm{ml})$ and was heated for 30 minutes. The solid formed, after cooling, was filtered, washed with dil. $\mathrm{HCl}$ and recrystallized using ethanol to obtain the corresponding arylhydrazone. The arylhydrazone thus obtained by the above process was treated with the cold Vilsmeier-Haack reagent, prepared from $\mathrm{POCl}_{3}$ $\left(1 \mathrm{ml}, 0.28 \mathrm{~mol}\right.$ and DMF $(10 \mathrm{ml})$. It was stirred at $70-80{ }^{\circ} \mathrm{C}$ for $6 \mathrm{~h}$. After completion, it was poured in to ice-cold water after brought into ambient temperature. It was then neutralized by using saturated solutions of sodium bicarbonate, filtered, washed with water and dried to afford pure 4 [29].

\section{Synthesis of novel acrylonitrile 6}


To a mixture of carbaldehyde $4(0.5 \mathrm{~g}, 1.9 \mathrm{mmol})$ and benzimidazolyl acetonitrile $5(0.3 \mathrm{~g}, 1.9 \mathrm{mmol})$ in methanol, piperidine $(0.19 \mathrm{ml}, 1.9 \mathrm{mmol})$ was added. It was heated at 60 ${ }^{\circ} \mathrm{C}$ for $6 \mathrm{~h}$. After completion of reaction, as indicated by TLC, it was poured into water (ice-cold) and neutralized using $\mathrm{K}_{2} \mathrm{CO}_{3}$ (saturated solution). The precipitate formed was recrystallized from ethanol, after filtration followed by washed with water and dried, to give the target 6 . Yield, $89 \%$; MP: 315-316 ${ }^{\circ} \mathrm{C}$; FT-IR $\left(\mathrm{KBr}, \mathrm{cm}^{-1}\right): v$ 3295.4, 2190.5, $1705.6,1600.7,1531.3,1418.1,1368.5,1355.3,1244.5$, 1111.2, 1052.7, 969.6, 856.5, 813.3, 757.0, 677.7, 663.5, 635.3, 497.6; ${ }^{1} \mathrm{H}$ NMR (400 MHz, $\left.\mathrm{CDCl}_{3}\right): \delta 8.75(\mathrm{t}, J=4$ $\mathrm{Hz}, 2 \mathrm{H}), 8.48$ (s, 1H), 7.64-7.55 (m, 8H), 7.34-7.17 (m, 5H), 2.35 (s, 3H); ${ }^{13} \mathrm{C}$ NMR (100 MHz, $\left.\mathrm{CDCl}_{3}\right): \delta 150.5,143.3$, 139.3, 129.9, 129.8, 129.5, 128.5, 123.4, 128.3, 127.1, 126.9, 125.3, 123.7, 119.1; EI-MS (e/z): 401 (M+).

\section{RESULTS AND DISCUSSION}

\section{Chemistry}

\section{A. Synthesis and characterization}

In the first part, we have synthesized compound $\mathbf{4}$ from p-methyl acetophenone (1) through a two-step process. Condensation of hydrazine $\mathbf{2}$ with ketone $\mathbf{1}$ followed by cyclization and formylation using Vilsmeier Haack reagent yielded 4. The carbaldehyde 4, upon Knoevenagel condensation with the active methylene group of $\mathbf{5}$ in methanol using piperidine catalyst under reflux condition gave the target acrylonitrile 6 as shown in Scheme 1. The characteristic carbonyl vibrational frequency of aldehyde was absent in the IR spectra. Instead, a nitrile peak at $2190 \mathrm{~cm}^{-1}$ is visualized. Methyl proton was observed as three protons singlet at $\delta 2.35 \mathrm{ppm}$. All aromatic protons inclusive of $\mathrm{NH}$ proton and newly formed $\mathrm{CH}$ proton appeared in the region $\delta$ 7.17-8.75 ppm in the ${ }^{1} \mathrm{H}$ NMR spectra. ${ }^{13} \mathrm{C}$ NMR spectra has approved well with the structure of target compound.

\section{B. Geometry optimization}

The structural optimization of compound $\mathbf{6}$ was made using computational DFT/B3LYP [6-311G (d,p)] method. The optimized structure (ground state) is depicted in Fig. 1 and structural parameters (bond lengths, bond angles, and dihedral angles) are furnished in Tables 1 \& 2 . As exposed in Fig. 1, the molecular geometry of the parental pyrazole structural ornament has a typical butterfly form. The N25-H43, C17-Cl23, C19-Cl22, and C1-N4 bond lengths are $1.0071,1.7533,1.7533$ and $1.1549 \AA$ respectively agrees with the expected values $1.0(\mathrm{~N}-\mathrm{H}), 1.76(\mathrm{C}-\mathrm{Cl})$ and $1.16(\mathrm{CN})$. The bond angles between C8-C3-H33, C2-C3-C8, C3-C8-C9, and C3-C2-C24 are 114.233, 130.171, 130.124 and 127.719, respectively.

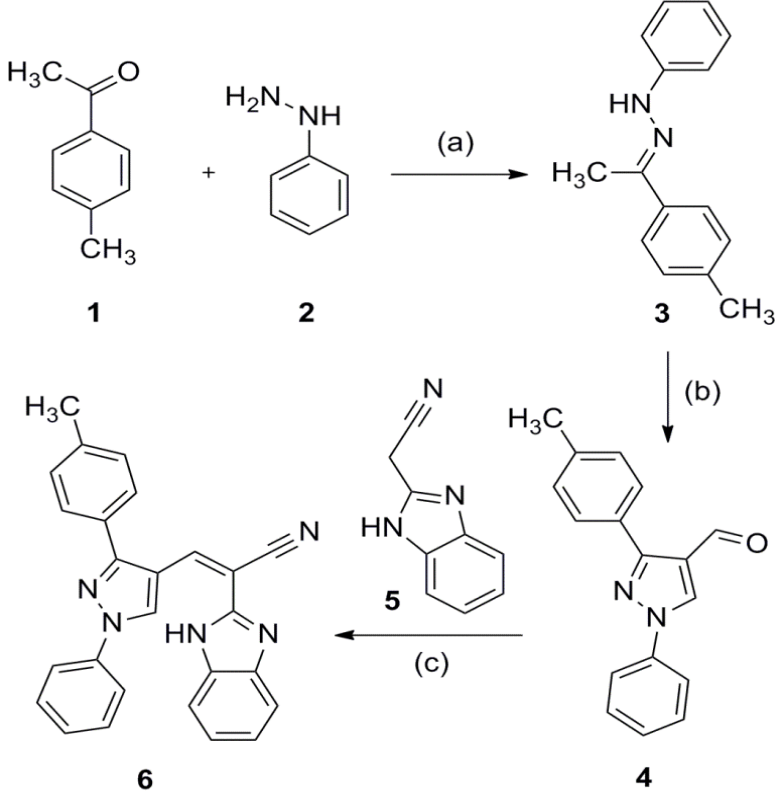

Scheme 1. Snythesis of acrylonitrile 6: Reagents and conditions: (a) Glacial acetic acid, reflux, 30 mins; (b) $\mathrm{DMF}^{-\mathrm{POCl}_{3}, 70-80}{ }^{\circ} \mathrm{C}, 6 \mathrm{~h}$; (c) piperidine, methanol, 60 $\left.{ }^{\circ} \mathrm{C}, 6 \mathrm{6h}\right)$.

\section{Computational details}

The computational calculations of the molecule 6 have been performed employing DFT-B3LYP; 6-311G (d,p) method [30]. Optimized molecular geometry, FMO energy levels, MEP, Mulliken atomic charge distributions and NLO properties of compound $\mathbf{6}$ were derived from the computational details.

\section{Optimized geometry}

The ground state optimized geometry of compound $\mathbf{6}$ has been computed using DFT/B3LYP [6-311G (d,p)]. The theoretically obtained optimized parameters such as bond lengths and bond angles are shown in Tables $\mathbf{1} \& \mathbf{2}$, respectively. The optimized structure is shown in Fig 1. The N24-H46 and C1-N4 bond lengths are 1.0073, and $1.1549 \AA$ respectively approves with the anticipated values $1.0(\mathrm{~N}-\mathrm{H})$, and $1.16(\mathrm{CN})$. The bond angles between $\mathrm{C} 2-\mathrm{C} 3-\mathrm{C} 8$, C7-C10-C13, N5-C17-C22 and C2-C23-N27 are 129.7903, $121.7801,119.3125$ and 123.9935 degrees respectively, thus, the molecule is planar with slight deviation in bond angles are observed due to optimization in gas phase.
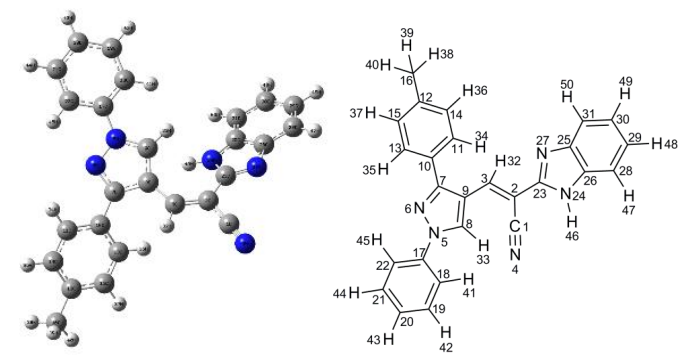

Fig. 1. Optimized Structure of 6 
International Journal of Engineering and Advanced Technology (IJEAT) ISSN: 2249 - 8958, Volume-9, Issue-1S4, December 2019

Table 1: Computed Bond length of 6

\begin{tabular}{llll}
\hline \multicolumn{1}{c}{ Bond } & \multicolumn{1}{c}{$[\AA]$} & \multicolumn{1}{c}{ Bond } & {$[\AA]$} \\
\hline C1-C2 & 1.4339 & C16-H40 & 1.0916 \\
C1-N4 & 1.1549 & C17-C18 & 1.3967 \\
C2-C3 & 1.3608 & C17-C22 & 1.3961 \\
C2-C23 & 1.4669 & C18-C19 & 1.3915 \\
C3-C8 & 1.45 & C18-H41 & 1.0827 \\
C3-H32 & 1.0852 & C19-C20 & 1.3927 \\
N5-N6 & 1.3562 & C19-H42 & 1.0837 \\
N5-C9 & 1.356 & C20-C21 & 1.3938 \\
N5-C17 & 1.4234 & C20-H43 & 1.0835 \\
N6-C7 & 1.3285 & C21-C22 & 1.3903 \\
C7-C8 & 1.4384 & C21-H44 & 1.0838 \\
C7-C10 & 1.4706 & C22-H45 & 1.0807 \\
C8-C9 & 1.3887 & C23-N24 & 1.3828 \\
C9-H33 & 1.0761 & C23-N27 & 1.3133 \\
C10-C11 & 1.4038 & N24-C25 & 1.3808 \\
C10-C13 & 1.4003 & N24-H46 & 1.0073 \\
C11-C14 & 1.3868 & C25-C26 & 1.4156 \\
C11-H34 & 1.0828 & C25-C31 & 1.3947 \\
C12-C14 & 1.4015 & C26-N27 & 1.3806 \\
C12-C15 & 1.3961 & C26-C28 & 1.3997 \\
C12-C16 & 1.5086 & C28-C29 & 1.3871 \\
C13-C15 & 1.3924 & C28-H47 & 1.083 \\
C13-H35 & 1.0835 & C29-C30 & 1.4086 \\
C14-H36 & 1.0855 & C29-H48 & 1.0838 \\
C15-H37 & 1.0849 & C30-C31 & 1.3898 \\
C16-H38 & 1.0934 & C30-H49 & 1.0839 \\
C16-H39 & 1.0952 & C31-H50 & 1.0839 \\
\hline & & & \\
\hline & & & \\
\hline
\end{tabular}

Table 2: Computed Bond angle of 6

\begin{tabular}{llll}
\hline Bond Angles & {$[$ ㅇ] } & Bond Angles & {$[$ [ $]$} \\
\hline C1-C2-C3 & 117.320 & N5-C17-C18 & 120.295 \\
C1-C2-C23 & 115.008 & N5-C17-C22 & 119.312 \\
C3-C2-C23 & 127.648 & C18-C17-C22 & 120.392 \\
C2-C3-C8 & 129.790 & C17-C18-C19 & 119.523 \\
C2-C3-H32 & 115.728 & C17-C18-H41 & 120.759 \\
C8-C3-H32 & 114.446 & C19-C18-H41 & 119.706 \\
N6-N5-C9 & 111.914 & C18-C19-C20 & 120.481 \\
N6-N5-C17 & 120.252 & C18-C19-H42 & 119.292 \\
C9-N5-C17 & 127.830 & C20-C19-H42 & 120.222 \\
N5-N6-C7 & 105.931 & C19-C20-C21 & 119.540 \\
N6-C7-C8 & 110.809 & C19-C20-H43 & 120.180 \\
N6-C7-C10 & 120.468 & C21-C20-H43 & 120.278 \\
C8-C7-C10 & 128.721 & C20-C21-C22 & 120.630 \\
C3-C8-C7 & 126.666 & C20-C21-H44 & 120.093 \\
C3-C8-C9 & 128.701 & C22-C21-H44 & 119.275 \\
C7-C8-C9 & 103.933 & C17-C22-C21 & 119.424 \\
N5-C9-C8 & 107.407 & C17-C22-H45 & 119.082 \\
N5-C9-H33 & 122.089 & C21-C22-H45 & 121.492 \\
C8-C9-H33 & 130.308 & C21-C22-H45 & 121.492 \\
C7-C10-C11 & 120.045 & C2-C23-N27 & 123.993 \\
C7-C10-C13 & 121.780 & N24-C23-N27 & 112.482 \\
C11-C10-C13 & 118.168 & C23-N24-C25 & 107.150 \\
C10-C11-C14 & 120.705 & C23-N24-H46 & 125.764 \\
C10-C11-H34 & 118.979 & C25-N24-H46 & 126.981 \\
C14-C11-H34 & 120.314 & N24-C25-C26 & 104.559 \\
C14-C12-C15 & 117.846 & N24-C25-C31 & 132.951 \\
C14-C12-C16 & 120.794 & C26-C25-C31 & 122.489 \\
C15-C12-C16 & 121.355 & C25-C26-N27 & 110.289 \\
C10-C13-C15 & 120.727 & C25-C26-C28 & 119.825 \\
C10-C13-H35 & 120.099 & N27-C26-C28 & 129.884 \\
C15-C13-H35 & 119.151 & C23-N27-C26 & 105.515 \\
C11-C14-C12 & 121.307 & C26-C28-C29 & 117.979 \\
C11-C14-H36 & 119.293 & C26-C28-H47 & 120.065 \\
C12-C14-H36 & 119.397 & C29-C28-H47 & 121.954 \\
C12-C15-C13 & 121.237 & C28-C29-C30 & 121.425 \\
& & &
\end{tabular}

\begin{tabular}{llll}
$\mathrm{C} 12-\mathrm{C} 15-\mathrm{H} 37$ & 119.535 & $\mathrm{C} 28-\mathrm{C} 29-\mathrm{H} 48$ & 119.590 \\
$\mathrm{C} 13-\mathrm{C} 15-\mathrm{H} 37$ & 119.225 & C30-C29-H48 & 118.984 \\
$\mathrm{C} 12-\mathrm{C} 16-\mathrm{H} 38$ & 111.333 & C29-C30-C31 & 121.654 \\
$\mathrm{C} 12-\mathrm{C} 16-\mathrm{H} 39$ & 110.962 & C29-C30-H49 & 119.163 \\
$\mathrm{C} 12-\mathrm{C} 16-\mathrm{H} 40$ & 111.431 & $\mathrm{C} 31-\mathrm{C} 30-\mathrm{H} 49$ & 119.181 \\
$\mathrm{H} 38-\mathrm{C} 16-\mathrm{H} 39$ & 107.215 & $\mathrm{C} 25-\mathrm{C} 31-\mathrm{C} 30$ & 116.626 \\
$\mathrm{H} 38-\mathrm{C} 16-\mathrm{H} 40$ & 108.087 & $\mathrm{C} 25-\mathrm{C} 31-\mathrm{H} 50$ & 122.071 \\
$\mathrm{H} 39-\mathrm{C} 16-\mathrm{H} 40$ & 107.622 & $\mathrm{C} 30-\mathrm{C} 31-\mathrm{H} 50$ & 121.301 \\
\hline
\end{tabular}

\section{E. Mulliken charge distribution}

The partial atomic charges can be predictable from Mulliken population analysis method. Also, it helps to determine the ability of an atom to be attacked by an electrophile or nucleophile. Thus, the optimized structure of compound $\mathbf{6}$ was computed and the atomic charges are shown in Table 3. Fig. 2 indicates the distribution of clear atomic charge of $\mathbf{6}$, symbolized by coloring. The charge distributions of the atoms imply the formation of acceptor and donor pairs relating the charge transfer in the molecule $[31,32]$. In $\mathbf{6}$, the $\mathrm{C} 7$ and $\mathrm{C} 23$ atoms have more positive charges signifying that these regions are susceptible for nucleophilic attack or they are called as nucleophilic attack regions, whereas the nitrogen, N24, carbon, C8 have more negative charges compared to other atoms indicative of electrophilic attack prone site. The Mulliken population chart of charge distributions of compound 6 was shown in Fig. 3.

Table 3: Mulliken Atomic Charges of Compound 6

\begin{tabular}{cccc}
\hline Atom & Charges & Atom & Charges \\
\hline C1 & 0.075762 & C26 & -0.016674 \\
C2 & -0.04195 & N27 & -0.323222 \\
C3 & -0.01457 & C28 & -0.060469 \\
N4 & -0.22307 & C29 & -0.103199 \\
N5 & -0.33423 & C30 & -0.108966 \\
N6 & -0.25251 & C31 & -0.057913 \\
C7 & 0.315071 & H32 & 0.145064 \\
C8 & -0.41143 & H33 & 0.139120 \\
C9 & 0.227653 & H34 & 0.100317 \\
C10 & -0.08557 & H35 & 0.105021 \\
C11 & -0.02955 & H36 & 0.088141 \\
C12 & -0.09294 & H37 & 0.090875 \\
C13 & -0.07215 & H38 & 0.120971 \\
C14 & -0.08019 & H39 & 0.129966 \\
C15 & -0.07449 & H40 & 0.110733 \\
C16 & -0.25547 & H41 & 0.111074 \\
C17 & 0.215705 & H42 & 0.104112 \\
C18 & -0.11212 & H43 & 0.102549 \\
C19 & -0.09916 & H44 & 0.104683 \\
C20 & -0.07982 & H45 & 0.129211 \\
C21 & -0.09833 & H46 & 0.248706 \\
C22 & -0.06301 & H47 & 0.103686 \\
C23 & 0.316713 & H48 & 0.096854 \\
N24 & -0.46800 & H49 & 0.096947 \\
C25 & 0.187097 & H50 & 0.093066 \\
\hline
\end{tabular}




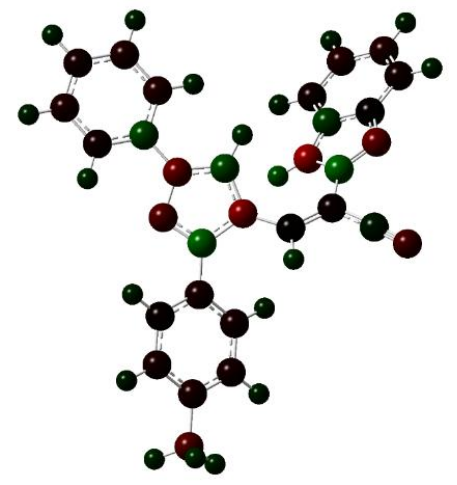

Fig. 2. Optimized Structure and Mulliken charge distribution of 6

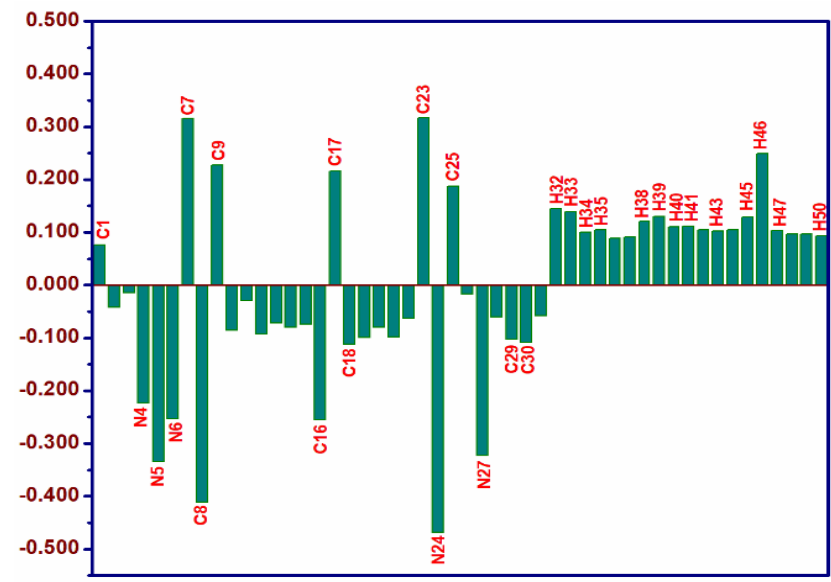

Fig. 3. Mulliken charge distribution Chart of 6

\section{F. HOMO-LUMO Analysis}

The electronic structure of target molecules and charge transport properties are conceived from HOMO-LUMO energy gap [33]. Huge variance in HOMO-LUMO values specifies that target compound is stable. The electron spreading on FMOs viz., HOMO-2-LUMO+2, HOMO-1-LUMO+1, and HOMO-LUMO energy levels of compound $\mathbf{6}$ is furnished in Fig. 4 (energy values are provided in Table 4). Fig 4 reveals the possibilities of inter-electron transfer within the molecule. In the HOMO, the orbitals spread over the entire molecule while in LUMO its concentration is large on the nitrile part. In the case of HOMO-1, the orbital localization over the entire molecule is larger while the same is true on the pyrazole part in LUMO+1. On the other hand, in the case of HOMO-2, the orbitals are precisely located on the benzimidazole scaffold while in LUMO+2, the same is precisely located on phenyl ring connected to pyrazole scaffold. All these characteristics support the electron transfer with the molecule.

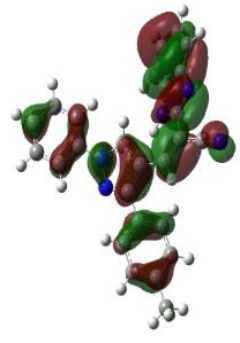

HOMO

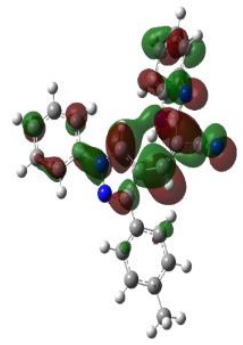

LUMO

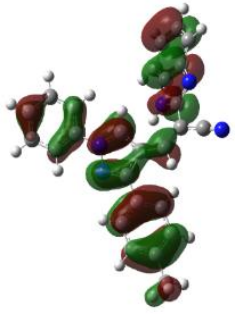

HOMO-1

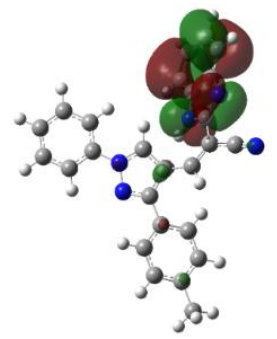

HOMO-2

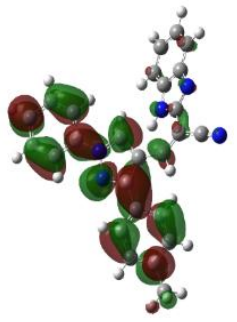

LUMO+1

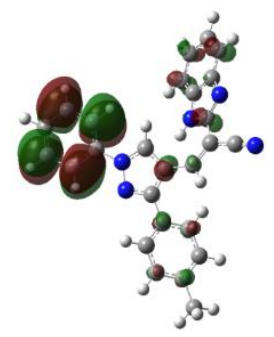

$\mathrm{LUMO}+2$

Fig. 4. 3D Plots of FMO of 6

Table 4. Calculated Molecular Orbital Energies of 6

\begin{tabular}{ll}
\hline Parameters & \multicolumn{1}{c}{$(\mathbf{e V})$} \\
\hline HOMO & -6.1073 \\
LUMO & -2.4082 \\
$\Delta \mathrm{E}$ & 3.6991 \\
HOMO-1 & -6.5857 \\
LUMO+1 & -1.5470 \\
$\Delta \mathrm{E} 1$ & 5.0387 \\
HOMO-2 & -6.5990 \\
LUMO+2 & -0.9396 \\
$\Delta \mathrm{E} 2$ & 5.6594 \\
\hline
\end{tabular}

\section{G. Non-linear optical characteristics}

The dipole moment, polarizability and first order hyperpolarizabilities of $\mathbf{6}$ were determined through computational calculations and the results obtained were compared with the non-linear optical molecule urea, considered as a standard. Normally, the NLO molecules exhibit superior first order hyperpolarizability, molecular polarizability, and dipole moment values. The parameters of NLO of the target $\mathbf{6}$ are furnished in Table 5.

Table 5. NLO Parameters of 6

\begin{tabular}{ll}
\hline Parameters & Values \\
\hline Dipole moment & \\
$\mu_{\mathrm{x}}$ & 1.9401 \\
$\mu_{\mathrm{v}}$ & 6.7079 \\
$\mu_{\mathrm{7}}$ & 3.2874 \\
$\mu(\mathrm{D})$ & 7.7179 \\
Polarizability & \\
$\alpha_{\mathrm{xx}}$ & -156.8089 \\
$\alpha_{\mathrm{vv}}$ & -188.1295 \\
$\alpha_{77}$ & -187.7466 \\
$\alpha_{\mathrm{total}}$ & $4.0515 \times 10^{-23}$ \\
& \\
&
\end{tabular}


$\alpha_{n}$

$-177.5617$

Hyper-polarizability

\begin{tabular}{ll}
$\beta_{\mathrm{xxx}}$ & 63.2960 \\
$\beta_{\mathrm{xxv}}$ & -4.5856 \\
$\beta_{\mathrm{xvv}}$ & 54.3708 \\
$\beta_{\mathrm{vvv}}$ & 258.4406 \\
$\beta_{\mathrm{xx}}$ & 30.6724 \\
$\beta_{\mathrm{xv}}$ & -7.1321 \\
$\beta_{\mathrm{vv} 7}$ & 67.6870 \\
$\beta_{\mathrm{x} 77}$ & -2.9004 \\
$\beta_{\mathrm{vz7}}$ & 25.6297 \\
$\beta_{\mathrm{z77}}$ & 23.9072 \\
$\beta_{0}$ & $2.81583 \times 10^{-30}$ \\
\hline
\end{tabular}

The calculated hyperpolarizability, polarizability and total dipole moment values of 6 are found to be and $2.81583 \times 10^{-30}$ esu, $4.0515 \times 10^{-23}$ Debye-Ang and 7.7179 Debye, respectively whereas the NLO molecule, urea was reported to have hyperpolarizability $\left(0.37 \times 10^{-30} \mathrm{esu}\right)$ and dipole moment $(\mu=1.3732$ D) [34]. Thus, compound 6 shows 5.6 -fold increases in dipole moment and 7.6 time increase in hyperpolarizability value than the urea molecule. This indicates that the compound $\mathbf{6}$ could serve as an NLO material or could serve as a template to construct efficient NLO materials.

\section{H. Molecular electrostatic potential analysis}

The molecular electrostatic potential of a compound is associated to density of electrons, which connects molecule's reactivity the nature of the molecule's regulation [35]. The molecular electrostatic potential formed in space is a prime factor in understanding the approachable positions for nucleophile, electrophile and hydrogen bonding interactions [36]. The molecular electrostatic potential can easily be read (color map; red - lowest electrostatic potential; blue - highest electrostatic potential energy values). MEP map of 6 was gained from the optimized operational calculation.

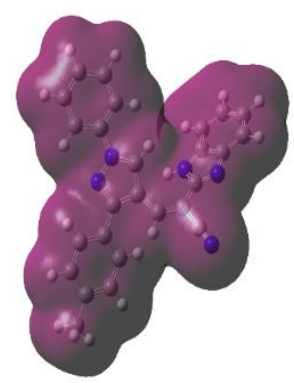

ED

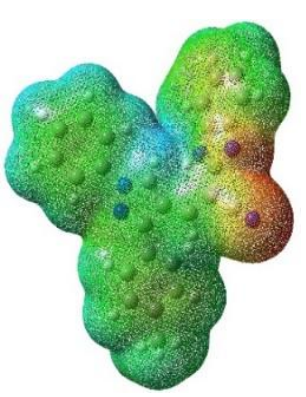

MEP

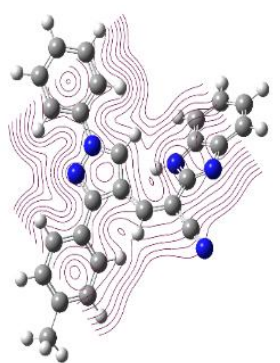

ED with Coutour

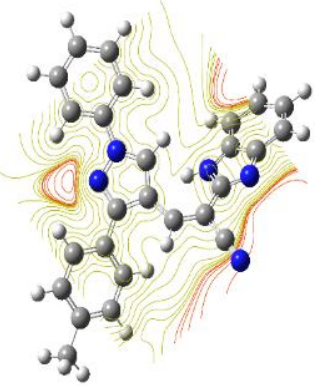

\section{CONCLUSION}

To conclude, we have successfully synthesized and characterized a novel acrylonitrile $\mathbf{6}$. The target molecule $\mathbf{6}$ was computed using DFT- B3LYP [6-311++ G(d,p)]. Further, structural optimization, mulliken charges, MEP analysis, HOMO-LUMO analysis and related parameters were determined. Additionally, the NLO properties were also determined by computing polarizability and hyperpolarizability values and compared the respective values of urea molecule. Thus, the novel acrylonitrile 6 could either serve as potent NLO material or could serve as a building block to construct effective NLO material.

\section{ACKNOWLEDGMENT}

Financial assistance provided by the Indian Council of Medical research (No.58/16/2013-BMS), New Delhi, India is gratefully acknowledged.

\section{REFERENCES}

[1] D. Hwang, S. Kim, M. Park, J. Lee, B. Koo, I. Kang, S. Kim, T. Zyung, "Conjugated polymers based on phenothiazine and fluorene in light-emitting diodes and field effect transistors," Chem. Mater., vol. 16, pp. 1298-1303, Mar 2004

[2] H. Jiang, J. Sun, "Synthesis and characterization of a novel spirocyclic aromatic derivative: unique roles of phenothiazine," New J. Chem. vol. 37, pp. 3161-3165, Jul 2013

[3] X. Kong, A. P. Kulkarni, S. A. Jenekhe, "Phenothiazine-based conjugated polymers: synthesis, electrochemistry, and light-emitting properties," Macromolecules, vol. 36, pp. 8992-8999, Nov 2003.

[4] J. Zhang, B. Xu, J. Chen, L. Wang, W. Tian, "Oligo (phenothiazine) s twisted intramolecular charge transfer and aggregation-induced emission," J. Phys. Chem., C, vol. 117, pp. 23117-23125, Sep 2013.

[5] A. S. Hart, C. Bikram, N. K. Subbaiyan, P. A. Karr, F. D'Souza, "Phenothiazine-sensitized organic solar cells: effect of dye anchor group positioning on the cell performance," ACS Appl. Mater. Interfaces., vol. 4, pp. 5813-5820, Oct 2012.

[6] W. Zhou, Y. Wen, L. Ma, Y. Liu, X. Zhan, "Conjugated polymers of rylene diimide and phenothiazine for n-channel organic field-effect transistors," Macromolecules, vol. 45, pp. 4115-4121, May 2012.

[7] Y. Zou, W. Wu, G. Sang, Y. Yang, Y. Liu, Y. Li, "Polythiophene derivative with phenothiazine- vinylene conjugated side chain Synthesis and its application in field-effect transistors," Macromolecules, vol. 40, pp. 7231-7237, Aug 2007.

[8] B. Chiou, Y. Tsai, C.M. Wang, "Phenothiazine-modified electrodes: a useful platform for protein adsorption study," Langmuir, vol. 30, pp 1550-1556, Jan 2014.

[9] K. Singh, R. Thakur, V. Kumar, "Co(II), Ni(II), Cu(II), and $\mathrm{Zn}(\mathrm{II})$ complexes derived from 4-[\{3-(4-bromophenyl)-1-phenyl1H-pyrazol-4-ylmethylene \}-amino]-3-mercapto-6-methyl-5-oxo-1,2,4 -triazine," J. Basic and Appl. Sci., vol. 5, pp. 21-30, Mar 2016.

[10] S. Malladi, A. M. Isloor, S. Isloor, D. S. Akhila, H.-K. Fun, Synthesis, characterization and antibacterial activity of some new pyrazole based Schiff bases, Arabian J. Chem., vol. 6, pp. 335-340, Jul 2013

[11] N. Ribeiro, S. Roy, N. Butenko, I. Cavaco, T. Pinheiro, I. Alho, F. Marques, F. Avecilla, J. Costa Pessoa, I. Correia, "New Cu (II) complexes with pyrazolyl derived Schiff base ligands: synthesis and biological evaluation," J. Inorg. Biochem., vol. 174, pp. 63-75, Sep 2017.

[12] V. Kanagarajan, M. R. Ezhilarasi, M. Gopalakrishnan, “'One-pot' ultrasound irradiation promoted synthesis and spectral characterization of an array of nove 1,1'-(5,5'-(1,4-phenylene)bis(3-aryl-1H-pyrazole-5,1(4H,5H)-diyl))di ethanones, a bisacetylated pyrazoles derivatives," Spectrochim. Acta Mol. Biomol. Spectrosc., vol. 78, pp. 635-639, Feb 2011.

Fig. 5. MEP map of 6 


\section{Synthesis, Characterization and DFT Analysis of Benzimidazolylpyrazolylacrylonitrile}

[13] K. Singh, Y. Kumar, P. Puri, M. Kumar, C. Sharma, "Cobalt, nickel, copper and zinc complexes with 1,3-diphenyl-1H-pyrazole-4-carboxaldehyde Schiff bases: Antimicrobial, spectroscopic, thermal and fluorescence studies," Eur. J. Med. Chem., vol. 52, pp. 313-321, Jun 2012.

[14] X-H. Lv, Z-L. Ren, D-D. Li, B-F. Ruan, Q-S. Li, M-J. Chu, C-Y. Ai, D-H. Liu, K. Mo, H-Q. Cao, "Discovery of novel double pyrazole Schiff base derivatives as anti-tobacco mosaic virus (TMV) agents," Chin. Chem. Lett., vol. 28, pp. 377-382, Feb 2017.

[15] V. G. Vlasenko, G. G. Aleksandrov, D. A. Garnovskii, N. I. Makarova, S. I. Levchenkov, A.L. Trigub, Ya. V. Zubavichus, A. I. Uraev, Yu.V. Koshchienko, A. S. Burlov, "Mixed ligand metal-complexes of tridentate $\mathrm{N}, \mathrm{N}, \mathrm{S}$ pyrazole containing Schiff base and 2-amino-1-ethylbenzimidazole: Synthesis, structure, spectroscopic studies and quantum-chemical calculations," Polyhedron, 133, 245-256, Sep 2017.

[16] X. C. Gao, H. Cao, L. Q. Zhang, B. W. Zhang, Y. Cao and C. H. Huang, "Properties of a new pyrazoline derivative and its application in electroluminescence," J. Mater. Chem., vol. 9, pp. 1077-1080 1999.

[17] Burschka, F. Kessler, M. K. Nazeeruddin and M. Gratzel, "Co(III) Complexes as p-Dopants in Solid-State Dye-Sensitized Solar Cells," Chem. Mater., vol. 25, pp. 2986-2990, June 2013.

[18] U. M. Kauhanka and M. M. Kauhanka, "Synthesis of new liquid crystalline isoxazole-, pyrazole-and 2-isoxazoline-containing compounds," Liq. Cryst., vol. 33, pp. 121-127 August 2006.

[19] P.-T. Chou and Y. Chi, "Phosphorescent Dyes for Organic Light- Emitting Diodes," Chem. Eur. J., vol. 13, pp. 380-395, Dec 2006.

[20] R. A. Senthil, J. Theerthagiri, J. Madhavan and A. K. Arof, "Influence of pyrazole on the photovoltaic performance of dye-sensitized solar cell with polyvinylidene fluoride polymer electrolytes," Ionics, vol. 22, pp. 425-433, Mar 2016.

[21] B. Chandrakantha, A. M. Isloor, K. Sridharan, R. Philip, P. Shetty, M. Padaki, "Novel N-substituted-5-phenyl-1H-pyrazole-4-ethyl carboxylates as potential NLO materials" Arabian J. Chem., vol. 6, pp. 97-102, Jan 2013.

[22] H.-B. Liu, W.-W, Gao, V. K. R. Tangadanchu, C.-H. Zhou, R.-X Geng, "Novel aminopyrimidinyl benzimidazoles as potentially antimicrobial agents: design, synthesis and biological evaluation," Eur. J. Med. Chem., vol. 143, pp. 66-84, Jan 2018.

[23] H. Göker, G. Ayhan-Kilcigil, M. Tunçbilek, C. Kus, R. Ertan, E. Kendi, S. Özbey, M. Fort, C. Garcia, A. J. Farré, "Synthesis and antihistaminic $\mathrm{H} 1$ activity of 1, 2, 5 (6)-trisubstituted benzimidazoles," Heterocycles, vol. 51, pp. 2561-2573, 1999.

[24] M. Alp, H. Göker, R. Brun, S. Yıldız, "Synthesis and antiparasitic and antifungal evaluation of 2'-arylsubstituted-1H, 1' $\mathrm{H}-\left[\begin{array}{ll}2, & 5\end{array}\right]$ bisbenzimidazolyl-5-carboxamidines," Eur. J. Med. Chem., vol. 44, pp. 2002-2008, May 2009.

[25] H. Nakano, T. Inoue, N. Kawasaki, H. Miyataka, H. Matsumoto, T. Taguchi, N. Inagaki, H. Nagai, T. Satoh, "Synthesis and biological activities of novel antiallergic agents with 5-lipoxygenase inhibiting action," Bioorg. Med. Chem., vol. 8, pp. 373-380, Feb 2000.

[26] Z. Hu, L. Ou, S. Li, L. Yang, "Synthesis and biological evaluation of 1-cyano-2-amino-benzimidazole derivatives as a novel class of antitumor agents," Med. Chem. Res., vol. 23, pp. 3029-3038, Jun 2014.

[27] G. Ayhan-Kılcıgil, S. Gürkan, T. Çoban, E. D. Özdamar, B. Can-Eke, "Synthesis and Evaluation of Antioxidant Properties of Novel 2-[2-(4-chlorophenyl) benzimidazole-1-yl]-N-(2-arylmethylene amino) acetamides and 2-[2-(4-chlorophenyl) benzimidazole-1-yl]-N-(4-oxo-2-aryl-thiazolidine-3-yl) acetamides-I," Chem. Biol. Drug Design, vol. 79, pp. 869-877, April 2012.

[28] N. Sudha, B. Abinaya, R. Arun Kumar, R. Mathammal, "Synthesis, Structural, Spectral, Optical and Mechanical Study of Benzimidazolium Phthalate crystals for NLO Applications," J. Laser. Opt. Photonics, vol. 5, pp. 1-6, May 2018.

[29] S. Bansal, M. Bala, S. K. Suthar, S. Choudhary, S. Bhattacharya, V. Bhardwaj, S. Singla, A. Joseph, "Design and synthesis of novel 2-phenyl-5-(1, 3-diphenyl-1H-pyrazol-4-yl)-1, 3, 4-oxadiazoles as selective COX-2 inhibitors with potent anti-inflammatory activity," Eur. J. Med. Chem., vol. 80, pp. 167-174, Jun 2014.

[30] M. J. Frisch, G. W. Trucks, H. B. Schlegel, G. E. Scuseria, M. A. Robb, J. R. Cheeseman, et. al, Gaussian Inc, Wallingford CT, Gaussian 09, Revision D.01, 2009.
[31] R. S. Mulliken, "Electronic Population Analysis on LCAO-MO Molecular Wave Functions. I," J. Chem. Phys., 1955, vol. 23, pp. 1833-1840, December 1955.

[32] R. S. Mulliken, "Molecular Compounds and Their Spectra. V. Orientation in Molecular Complexes," J. Chem. Phys., vol. 23, pp. 1841-1846, December 1955.

[33] I. Fleming, "Frontier Orbitals and Organic Chemical Reactions," Wiley-Blackwell, New York, 1976

[34] M. Nakano, I. Shigemoto, S. Yamada, K. Yamaguchi, "Size-consistent approach and density analysis of hyperpolarizability: Second hyperpolarizabilities of polymeric systems with and without defects," J. Chem. Phys., vol. 103, pp. 4175-4191, May 1995.

[35] P. Politzer, P. R. Laurence, K. Jayasuriya, "Molecular electrostatic potentials: an effective tool for the elucidation of biochemical phenomena," Environ. Health Perspect, vol. 61, pp. 191-202, Sep 1985.

[36] K. Wu, J. G. Snijders, C. Lin, "Reinvestigation of hydrogen bond effects on the polarizability and hyperpolarizability of urea molecular clusters," J. Phys. Chem., B, vol. 106, pp. 8954-8958, Aug 2002.

\section{AUTHORS PROFILE}

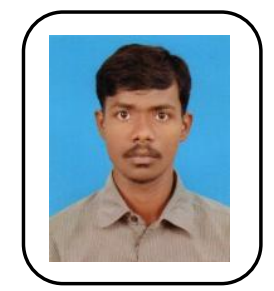

Ramar Sivaramakarthikeyan earned his BSc degree in Chemistry from VHNSN College, Virudhunagar, affiliated to Madurai Kamaraj University, Tamilnadu, India in 2013. He completed his MSc in Chemistry in 2015 from Kalasalingam Academy of Research and Education, Krishnankoil. Currently he is pursuing $\mathrm{PhD}$ at Kalasalingam Academy of Research and Education, Krishnankoil. He has been working in the area of biopertinent heterocycles.

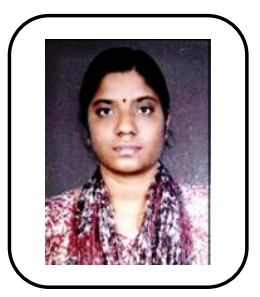

Krishnaraj Padmavathy received her Bachelor of Science degree in Chemistry from Bharathidasan college for women, Pondicherry in 2004. She obtained her Master's degree from Kanchi Mamunivar Centre for Postgraduate Studies, Pondicherry in 2006. She is currently a $\mathrm{PhD}$ student at Kalasalingam Academy of Research and Education, Krishnankoil, India. Her focus of research is methodology development and heterocyclic construction for biological applications.

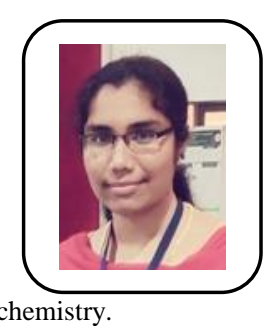

Shunmugam Iniyaval obtained her Bachelor of Science degree in Chemistry from Sri Parasakthi College for Women, Courtallam in 2013. She earned her Master's degree in Chemistry in 2015 from Sri Paramakalyani College, Alwarkuruchi. She is currently a PhD student at Kalasalingam Academy of Research and Education, Krishnankoil. She has been working in the area of heterocyclic synthesis and medicinal

chemistry.

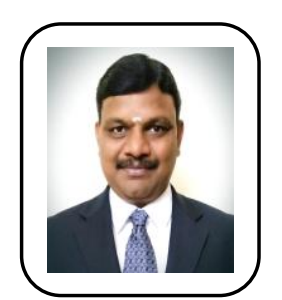

Dr. Chennan Ramalingan is serving as Professor of Chemistry at KARE. He received his $\mathrm{PhD}$ in Organic Chemistry from Annamalai University (2002). After he served as Research Professor at Kyungpook National University, South Korea followed by Assistant Professor at Osaka University, Japan (8 years), he joined at Kalasalingam Academy of Research and Education, Krishnankoil (2011). His research interests include organic synthesis, medicinal chemistry and material chemistry. He published more than 70 International research articles. 